\title{
Promoting Healthy Lifestyle through Basic Psychological Needs in Inactive Adolescents: A Protocol Study from Self-Determination Approach
}

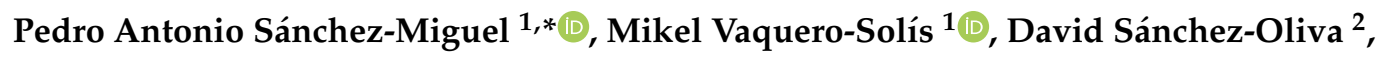 \\ Juan J. Pulido ${ }^{2}$, Miguel A. López-Gajardo ${ }^{2}\left(\mathbb{C}\right.$ and Miguel Angel Tapia-Serrano ${ }^{1, *(\mathbb{C})}$ \\ 1 Department of Didactics of Musical, Plastic and Body Expression, Faculty of Teaching Training, \\ University of Extremadura, 10071 Cáceres, Spain; mivaquero@alumnos.unex.es \\ 2 Department of Didactics of Musical, Plastic and Body Expression, Faculty of Sports Sciences, \\ University of Extremadura, 10071 Cáceres, Spain; davidsanchez@unex.es (D.S.-O.); jjpulido@unex.es (J.J.P.); \\ malopezgajardo@unex.es (M.A.L.-G.) \\ * Correspondence: pesanchezm@unex.es (P.A.S.-M.); matapiase@unex.es (M.A.T.-S.); \\ Tel.: +92-725-7049 (P.A.S.-M.)
}

Received: 1 June 2020; Accepted: 18 July 2020; Published: 22 July 2020

check for updates

\begin{abstract}
Prevalence of overweight and obesity is an important health problem worldwide. It was shown that physical activity and sedentary behaviour are associated with prevalence of overweight and obesity in youth individuals. However, few children and adolescents meet the World Health Organization recommendations about physical activity levels. The need to start promoting regular physical activity from an early age is crucial to avoid these problems. Therefore, the aim of the current research is to show a school-based motivational program for the promotion of healthy lifestyle in inactive adolescents grounded on Self-Determination Theory aimed at promoting physical activity adherence. The study is a quasi-experimental study (ClinicalTrials.gov ID: NCT03974607) aimed for adolescents from the 1st and 2nd high school level aged between 12 and 14 years old. The program will be based on the promotion of the three basics psychological needs: autonomy, competence and relatedness. The satisfaction of these needs is essential to fulfill the self-determined motivation and psychological well-being. The length of the sessions are $60 \mathrm{~min}, 3$ times per week, during 5 months. The sessions will be based on the participants' interests. Finally, this protocol will intend to change the perception of physical activity programs in order to focus the strategies on the motivational aspects, rather than physical activity itself as was usually conducted by previous programs
\end{abstract}

Keywords: motivation; youths; physical activity; protocol; intervention program; lifestyle

\section{Introduction}

According to the World Health Organization (WHO), overweight and obesity are defined as an abnormal or excessive accumulation of fat that can be harmful to health [1]. Prevalence of overweight and obesity is one of the most important public health issues worldwide because of the biological and psychosocial consequences they can cause [2]. Previous studies have found that lack of physical activity (PA) [2-4] and a sedentary behaviour [5,6] is associated with a higher prevalence of overweight and obesity in youth $[4,5]$.

Physical inactivity has been defined as decrease in body movement that produces decreased energy expenditure [7]. Based on Guthold et al. [8], the physical inactivity is considered doing less than $60 \mathrm{~min}$ of daily moderate-vigorous PA, or being active for less than $60 \mathrm{~min}$ for 5 days a week. The WHO has estimated the physical inactivity is the fourth risk factor to death in the world [1]. Moreover, $6 \%$ of 
the deaths registered annually in the world, as well as the reasons to promote some diseases (i.e., breast and colon cancer, diabetes, or heart disease), are caused by physical inactivity [2].

In Europe, 35\% of adolescents between 9 and 17 years old are insufficiently active and, and just $50 \%$ of 15 years old practice PA [9]. Thus, the need to start promoting regular PA at schools is emphasized. In this sense, the PA Promotion Model [10] suggest that the combination of individual-level factors (e.g., age, gender or socioeconomic status) and environmental/policy-level factors (e.g., family, school, peers.) can directly and indirectly influence in PA promotion and health-related behaviours. Thus, previous investigations $[11,12]$ have determined that more interventions promoting PA are needed for the creation of active schools. However, the previous reviews have determined that the school interventions to promote the PA in adolescents have a limited efficacy. Several reasons have been identified, for instance, socioeconomic status [13] and gender [5,14]. To overcome this limitation, the present study intends on promoting health-related behaviours in adolescents, independently of socioeconomic status and gender.

Therefore, taking into account the above, it would be logical to think that school is the best place to promote health-related behaviours, given that young people spend most of the day at school $[15,16]$. To prevent the problems caused by overweight and obesity, several school-based intervention have been developed to promote the health related behaviours in youths [11,14,17-21]. Intervention programs based on psychological theories have been more successful than those that do not take psychological variables into account e.g., [11,20]. Thus, psychological theories can provide key advances for intervention design as they facilitate the identification of key mediators and factors of behaviour change [22]. Furthermore, the Self-Determination Theory (SDT) suggests that school provides an opportunity to adopt a global approach to engage the entire school community in developing a health promotion program among adolescents [18]. According to the SDT, there are multiple sources of support that can influence the motivational results of students and, consequently, the initiation and maintenance of health-related behaviours [23]. SDT helps to explain the intention to develop and maintain these health-related behaviours, and therefore, it has been considered as a theory that can predict changes related to healthy habits [24]. In this sense, the systematic reviews conducted by Vaquero-Solís et al. [25] and Teixeira et al. [26] have shown a good evidence for the value of SDT in understanding and promoting PA. Both reviews showed a greater effectiveness of the interventions that were developed under the SDT perspective, taking into account the individuals' motivation.

Grounded in SDT, intervention as the Get Others Active (GoActive) [20], that was developed iteratively with adolescents and teachers with strategies based on peer support, self-efficacy, group cohesion, self-esteem and friendship quality and was implemented using a tiered-leadership system. The highlights of the GoActive study were the cluster randomised controlled trial design, objective measurement of PA in a large sample, the long-term follow-up post intervention and the assessment cost-effectiveness of the intervention and qualitative interviews with adolescents to know how to encourage them to participate in the intervention. Moreover, the CReActivity [11] intervention program was designed to promote girls' PA levels in Physical Education lessons. CReActivity highlighted the importance of implementing these interventions within Physical Education classes, adapting didactic contents and teaching methods to promote an active life in adolescents. In addition, it also took into account relevant issues such as socioeconomic status, environmental factors, characteristics of adolescents and body mass index.

In this regard, SDT [24] builds a theoretical framework of reference for the design of this protocol. This motivational theory has received significant attention in the investigation of the promotion of PA $[27,28]$. SDT is a macro-theory of human motivation that has helped explain activity participation. SDT highlights the students' basic psychological needs (autonomy, competence and relatedness) as inherent motivational assets that, when supported or satisfied, facilitate adaptive personal and social functioning [29]. Basic psychological needs (BPN) are considered essential to understand how teaching behaviours are related to the forms of students' motivation [30,31]. The psychological need for autonomy concerns a students' sense of initiative and ownership in one's actions [31]. 
Competence refers to the students' feeling of mastery, a sense that one can succeed and grow at tasks. Finally, relatedness concerns a students' sense of belonging and connection with other classmates [31]. According to the SDT, the social environments (i.e., teachers, parents, classmates) that support or thwart the BPN can influence the motivation of the adolescents [32], which contributes to the initiation and maintenance of healthy behaviours. Summing up, SDT stipulates that if the context promotes the support of the three BPNs, students are more likely to experience need satisfaction. Need satisfaction then leads to autonomous motivation for an activity where students engage in it because they want to, out of interest or curiosity [18]. Autonomous motivation (i.e., intrinsic, integrated and identified regulations) is the highest level of motivation, which refers to carrying out an activity because it is perceived as consistent with the person's intrinsic goals and is considered important or interesting. Students who experience need frustration are more likely to develop a controlled motivation for an activity where they do the activity in order to achieve a reward, please someone else or avoid guilt. Controlled motivation (i.e., introjected and external regulations) represents behaviour that arises from feelings of pressure, punishment, feelings of shame, external rewards or approval. Finally, amotivation refers to a lack of positive attitude and a sense of usefulness that is required to persist in the activity.

Regarding interventions based on SDT, some prospects have been pointed out to take into account for the future [33]—for example, the excess heterogeneity of the sample (i.e., age, gender, weight or body composition and fitness status), targeting population subgroups (such as girls [14] or low socioeconomic groups) [13], with low levels of PA or the short duration of interventions ( $<3$ months) [25,26]. Moreover, the decrease in PA occurs out of school [15]; however, many interventions have been target specific school-based time-for example, school time [34,35] or Physical Education lessons [36] or both in and out of school [20] whereas Multidisciplinary Program encourages participants to do more activity out of school based on SDT. In addition, SDT suggests that PA intervention programs which developed enjoyable and valued activities and foster perceptions of ownership, competence and belonging, are more likely to achieve sustained behaviour change [14].

Therefore, the present Multidisciplinary Program will provide a broad overview of factors associated with PA in adolescents and includes motivational constructs based on SDT such as autonomy, competence and relatedness, which has been found to be reliable and valid in the promotion of PA [37]. Finally, the aim of this study will be to assess the five-month effectiveness of the Multidisciplinary Program to increase PA and to promote health-related behaviour in adolescents.

\section{Methods}

\subsection{Design of the Study}

This research is a randomized study corresponding to: "Multidisciplinary Training Program for the Promotion of PA and Healthy Lifestyle in Inactive Adolescents". The trial registration: ClinicalTrials.gov ID: NCT03974607. Registered 19 August 2019. This is a longitudinal study, where different measurements were developed (initial and end of the program, as well as a follow-up) in order to obtain information and to check adolescents' health status in the Region of Extremadura. In addition, the collected information will be treated with the aim of analysing the effects of intervention programme for preventing overweight and obesity in adolescents.

The study will be carried out following the ethical guidelines of the Declaration of Helsinki and its 2013 modification and approved by the Human Research Ethics Committee of the University of Extremadura (89/2016).

\subsection{Participants}

Based on the previous investigations [20,38-40], the total number of participants expected to be reached is 2000 students. According to the number of students in Extremadura (Cáceres, Spain) in the Regional Statistic Bureau, the minimum number of participants was determined through that issue, taking into account a sampling error of $5 \%$ and a confidence level of $95.5 \%$. A total number of 2000 
participants is statistically enough. In Cáceres, most of the high schools have a total of four classes (two classes for first grade and two classes for second grade). Since each class has around 22 students, it is necessary for 23 schools to be able to recruit close to 2000 participants.

This research is intended for adolescents enrolled in 1st and 2nd grade of high school, aged between 12 and 14 years old. A random selection will be made of the 46 schools of Cáceres (Extremadura, Spain). After the selection of schools, a sample of around 2000 student participants (1000 boys and 1000 girls) will be expected to be obtained. Later, 120 students with all of the selection criteria will be recruited for the intervention programme and will be subdivided into the control group and experimental group. Each group will have 60 students-30 boys and 30 girls. Finally, the present study intends to promote health-related behaviours in adolescents, independently of socioeconomic status and gender.

\subsection{Procedure and Measure}

Figure 1 shows the phases into which the project is divided prior to the Multidisciplinary Program (intervention program). Previously, all students will carry out an assessment phase in order to know the daily PA and screen time (see inclusion criteria in Figure 1).

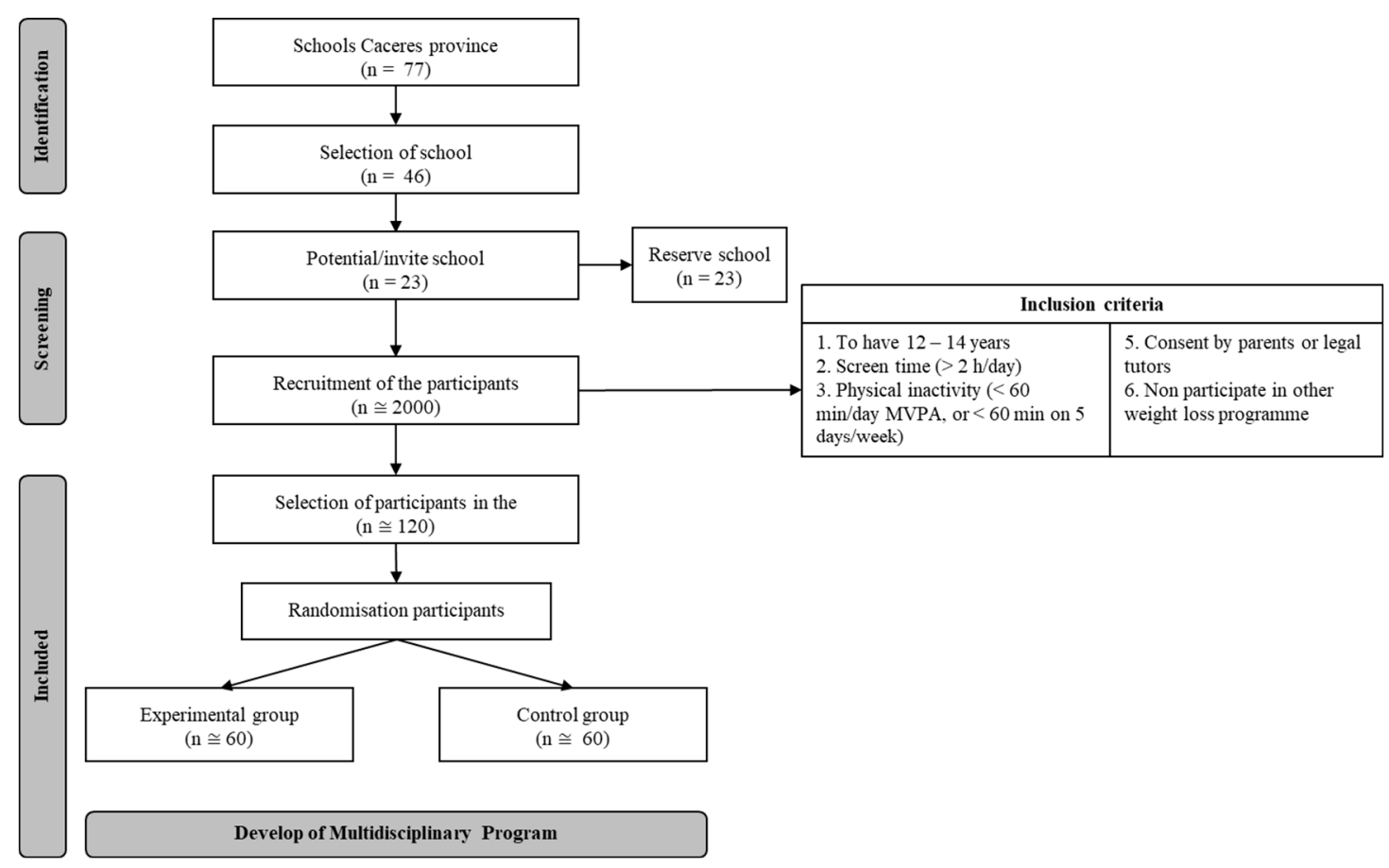

Figure 1. Procedure, phases and inclusion criteria of the program. Note. MVPA: Moderate-vigorous Physical Activity (PA).

Regarding recruitment, once the management team agrees to participate in the research, all students will be invited. Next, each student will be given a commitment document informing them of the research objectives so that they can give it to their parents or guardians. Therefore, participants who wish to participate in the study must present the commitment form signed by them and by the parents or guardians. This commitment document will be collected by the research team on the first day of measurements. All assessments will take place during the school day, so the teachers will not need to provide consent for the commuting of school time for data collection. 


\subsubsection{Procedure}

Identification: A random selection by computer will be made of the 46 schools of Cáceres (Extremadura, Spain). The first 23 schools will be selected as potential students and the next 23 schools will be included in a reserve list. The reserve schools will serve to replace the potential schools, in case they declined their participation.

The research team will inform by e-mail about the interest in participating in the research. Schools will have a maximum of 15 days to confirm their participation. If the supervisor does not respond or rejects participation in the project, the research team will contact corresponding reserve school. In addition, the supervisor team will be asked about the reasons that led them to make that decision. On the contrary, if they agree to participate, there will be a meeting with the research team in order to present the project and to establish dates for the evaluations. In addition, each tutor will be given a commitment sheet informing about the objectives and nature of the study. This sheet will be delivered to all students by their tutor and must be signed by both the student and his/her parent or guardian in order to participate in the study.

Screening: The research team will travel to participating schools to collect the research data. The commitment sheet signed by the students and the parent or guardian will be collected. Next, each student will be given a questionnaire packet in order to measure PA levels and screen time. The research team will ask the supervisor team to provide us a 30-min period of the school day to carry out measurements of sociodemographic, physical activity and screen time. It is expected that $30 \mathrm{~min}$ will be enough to develop the measurements. These measures will be used to identify the samples that do not meet with the PA daily guidelines for adolescents [41]; $<60 \mathrm{~min}$ of daily MVPA, or being active for less than $60 \mathrm{~min}$ on 5 days a week, $>2 \mathrm{~h}$ of screen time per day. Students who meet inclusion criteria (see Figure 1) will be invited to participle in the Multidisciplinary Program.

A total of 120 students will be recruited to the Multidisciplinary Program because previous researchers $[17,42-47]$ considered this an adequate, feasible and realistic sample size for this type of intervention.

Included: a simple randomization, unrestricted [31] will be developed of participants in control group (CG) and experimental group (EG). During randomization assignment, the assessment team (who will develop the evaluations) will be blinded to avoid contaminating data collection. Participants will be explicitly informed of the assigned group and will be reminded frequently not to disclose their set group. Finally, the Multidisciplinary Program will begin.

\subsubsection{Sociodemographic Measures, PA and Screen Time}

Sociodemographic measures. Students' self-reported age, grade and gender.

Self-reported PA. The PA level will be assessed with the PA Questionnaire for Adolescents (PAQ-A) [48]. This is a self-administered, 7-day recall instrument, with 9 items scored on a five-point scale. The PAQ-A provides a final composite activity score composed of the mean of the 9 items. This questionnaire has been shown to be valid and reliable [48,49]. Extracurricular PA is assessed with the Finnish PA Index [50]. It consists of 5 items concerning frequency and intensity of extracurricular PA and participation in organized sports. Using these five items, a PA index is calculated.

Screen time. The screen time will be measured using the Youth Leisure-time Sedentary Behaviour Questionnaire (YLSBQ) [51] with participants' self-reported time spent on TV, video games, computers and mobile phones both weekdays and weekend days. An average minutes/day of screen time of each behaviour will be calculated at a ratio of 5:2 (e.g., [Daily TV viewing on weekdays $\times 5$ ] + [Daily TV viewing on weekend days $\times 2] / 7$ ). Total daily screen time will be calculated summing the different daily screen time behaviours. 


\subsection{Multidisciplinary Program}

Table 1 shows the development of the Multidisciplinary Program. This program will be based on the promotion of the three basic psychological needs. According to the rationale of this proposal, in spite of many studies having exclusively analysed the incidence of autonomy-supportive (some of them also the thwarting style) on the BPN as a global factor in education generally $[52,53]$ and in Physical Education in particular [54,55], a recent meta-analysis has shown that teachers' autonomy support only predicted the need satisfaction for autonomy [56]. These findings highlight the importance of examining and including in the intervention program the teachers' competence and relatedness supports. Both competence and relatedness supports showed significant prediction on the three BPN [56]. In the same line, previous studies have already revealed that the support to the three BPN is a significant predictor of BPN as a global factor [57].

Table 1. Development of Multidisciplinary Program.

\begin{tabular}{|c|c|c|c|c|c|}
\hline & Initial Meeting & $\begin{array}{c}\text { Initial } \\
\text { Measure }\end{array}$ & $\begin{array}{l}\text { Development } \\
\text { of the Sessions }\end{array}$ & Final Measure & $\begin{array}{l}\text { Follow-Up Post } \\
\text { Intervention }\end{array}$ \\
\hline Control Group & & $\mathrm{X}$ & & $x$ & $\mathrm{X}$ \\
\hline Experimental Group & $x$ & $x$ & $x$ & $x$ & $x$ \\
\hline \multicolumn{6}{|c|}{ Assessment in Both Groups } \\
\hline \multicolumn{6}{|c|}{ Lifestyle variables } \\
\hline $\begin{array}{r}\text { Physical activity (se } \\
\text { Actigra }\end{array}$ & eported and & $x$ & & $x$ & $x$ \\
\hline Sedentary be & viour & $x$ & & $\mathrm{X}$ & $\mathrm{x}$ \\
\hline Body dissati & ction & $\mathrm{x}$ & & $\mathrm{x}$ & $\mathrm{x}$ \\
\hline Adherence to the $\mathrm{M}$ & iterrean diet & $x$ & & $\mathrm{x}$ & $x$ \\
\hline Regulation of behaviour & physical exercise & $x$ & & $x$ & $x$ \\
\hline Satisfaction & h life & $\mathrm{x}$ & & $\mathrm{x}$ & $\mathrm{x}$ \\
\hline Positive and neg & ive affect & $x$ & & $\mathrm{x}$ & $x$ \\
\hline \multicolumn{6}{|c|}{ Anthropometric measure } \\
\hline Weight and & ight & $\mathrm{x}$ & & $\mathrm{x}$ & $\mathrm{X}$ \\
\hline Skinfo & & $\mathrm{x}$ & & $x$ & $\mathrm{x}$ \\
\hline Waist circum & rence & $x$ & & $x$ & $x$ \\
\hline Neck circum & ence & $x$ & & $x$ & $x$ \\
\hline \multicolumn{6}{|c|}{ Physical fitness } \\
\hline Cardiorespirat & fitness & $\mathrm{x}$ & & $\mathrm{x}$ & $\mathrm{X}$ \\
\hline Handgrip st & ngth & $\mathrm{x}$ & & $\mathrm{x}$ & $\mathrm{x}$ \\
\hline Lower limb & ength & $x$ & & $x$ & $x$ \\
\hline Shuttle ru & & $x$ & & $\mathrm{X}$ & $x$ \\
\hline
\end{tabular}

Specifically, the strategies used to promote motivation and PA will be based on the satisfaction and support of BPN. In the field of education, autonomy support means nurturing their inner motivational resources by respecting their attitudes and suggestions (adopting the students' point of view to do an activity), providing rationales to attribute meaningfulness to learning (explaining why a task is important and where/when it could be used), relying on noncontrolling language, providing opportunities for choice, displaying patience to allow students the time they need for self-paced learning to occur and acknowledging and accepting expressions of negative affect [56,58]. In this sense, students will be asked about their interests and their points of view, giving them greater prominence during the sessions. Students will also be allowed to choose the activities that they liked the most or the ones that they would like to deepen their knowledge of. Moreover, teachers can use specific autonomy support strategies, referring to the use of cognitive teaching styles, to give responsibility for selecting tasks, as well as allowing the volition and the acknowledgment of the pupils' perspective. Competence support refers to the way the teacher organizes and delivers the activities in which the objectives of each task were adapted to the capacities of each participant, creating the opportunity for everyone to feel competent while being offered supportive feedback [56]. In this line, students will choose the activity in which he or she could develop with a sense of efficacy. For instance, teachers should propose different options to achieve the objectives of the tasks adjusted to the abilities of 
each one. Relatedness support (involvement) includes teachers taking time and resources to their students and using a considerate and warm approach to promote an inclusive learning environment, proposing cooperative and interdependent tasks [59]. In relation to this support, for example, teachers could create group work activities and cooperative work strategies will be used. This strategy will be based on creating learning contexts that develop the sense of inclusion, integration, trust and respect among participants. Besides, it is possible that monitor/trainers participate in the activities with the adolescents, in order to create a good sense of relatedness.

Finally, these needs will be thwarted if the authority figures (teachers) use a controlling style (e.g., Haerens et al. [39]), using coercion or pressure. Therefore, the program will consider the interests of participants to improve their autonomy, competence and relatedness, with the aim of having them persist in the activities.

In this sense, the Multidisciplinary Program aims to respond to some of the limitations found. For this, in relation to the duration, the program will develop over 5 months and will also establish inclusion criteria (mentioned Figure 1), in order to have a more homogeneous sample in relation to the levels of PA and sedentary behaviour.

\subsubsection{Justification of Duration, Volume, Frequency, Type PA and Load Training}

In recent years, many studies have been developed with the aim to promote the practice of PA among adolescents $[17,26,46,47,60]$. The PESSOA program developed by Quaresma et al. [47] aimed to explore the effects of social support and the type of motivational regulation during PA practice. After the intervention, the results showed higher levels in the motivational variables (extrinsic) and quality of life in the experimental group compared to the control group. However, the PA self-reported was an important limitation of this study. On the other hand, the "Sigue la Huella" program developed by Pardo et al. [17], managed to improve various health-related behaviours, after an intervention program based on promoting a healthy lifestyle. The systematic review conducted by Teixeira et al. [26] showed that PA programs based on SDT increased PA participation. However, when intrinsic motivation (e.g., affiliation and social engagement, challenge, skill development and perceived competence) is increased, more adaptive PA outcomes are shown.

With respect to limitations of previous studies, heterogeneity of samples with regard to factors such as age, gender, weight or body composition and fitness status were emphasized [26]. To ensure this heterogeneity, all students who have previously met the inclusion criteria for PA and screen time will be invited to participate in the program. Furthermore, given that a random sampling of the schools is carried out, the sample schools will choose from socio-demographically diverse areas. Moreover, the systematic review conducted by Vaquero-Solís et al. [25] identified that more intervention studies based on SDT are necessary in order to assess the effects on variables over time (more than 3 months).

The goal will be to meet with the PA recommendations [1] and guidelines of sedentary screen time based on 24-h movement for adolescents [41]. Previous studies [27,61,62] will be taken into account to establish duration, volume, frequency, type of PA and variation of the training load.

Duration: the program will last five months (twenty-three weeks) because this has been shown to be sufficient to increase PA levels in adolescents [44].

Volume: following the WHO recommendations [63], three 60-min sessions PA will be established, so that three 60-min sessions of mainly aerobic PA will be established. It is estimated that $150 \mathrm{~min} /$ week of moderate intensity aerobic PA (3-5.9 metabolic equivalents [MET, 1 MET $=3.5 \mathrm{~mL} \mathrm{O} / \mathrm{kg} / \mathrm{min}$ ]) equals $1000 \mathrm{kcal} /$ week, which is associated with lower rates of cardiovascular disease and premature mortality [64]. Therefore, individuals who fullfill these recommendations will have grater benefits for their health.

Frequency: three sessions per week will be developed because previous studies [64] have shown that is a good frequency to improve PA levels. In case any participant miss a class, they can develop it by him/herself according to the monitor suggestions. 
Type of PA: according to SDT, during the PA practice, it is easier to obtain positive experiences if the pleasure and satisfaction are higher. Therefore, the BPN will be improved by the higher interest in the activities [65]. Hence, the students will be questioned about the activities that they want to develop in the program. The main aim will be to increase the pleasure, enjoyment and satisfaction in order to meet the BPN, so the students will be asked about the activities they wish to practice every week. Considering the interest of the participants, the monitor will design playful and activities according to them, adapted to the physical fitness level of the students.

Variation of the training load: there will be a gradual progression to the training load. In addition, the first classes will aim to improve the socialization in the group, to encourage some of the SDT relatedness postulates.

\subsubsection{Initial Meeting}

To ensure greater assistance and participation, an initial meeting will be held with parents and participants to choose the three days of the week they prefer to practice. Moreover, the objectives and methodologies will be explained during the sessions. In addition, the research team will collect an authorization signed by participants' parents.

\subsubsection{Initial Measure}

This phase will aim to determine the initial levels of physical fitness and the psychosocial and anthropometric variables. It will develop during the first week in both groups. It is expected that 30 min will be enough to develop the measurements (see supplementary file: variables and instruments of the initial measure).

(A) Sociodemographic measures

Sociodemographic measures. Students' self-reported age, gender and socioeconomic status. Socioeconomic status was reported by the Family Affluence Scale II [66]. A socioeconomic indicator (0-9 range) was calculated as a continuous variable by summing the four possible responses.

(B) Lifestyle variables

Self-reported PA level and sedentary behaviour. Explained in the section screening.

Accelerometer-device PA information. The ActiGraph accelerometer model GT3X + (Actigraph TM, LLC, Fort Walton Beach, FL, USA) will be used to obtain detailed and objective information about daily PA and sedentary behaviour over seven consecutive days. Previous studies have revealed strong agreement between measures from GT3X + activity monitors without needing additional calibration [67,68] and have reported that these instruments are technically reliable [69]. The accelerometer is attached tightly at the back of the hip, with the notch facing upwards, and participants are instructed to use the accelerometer during waking hours and remove it during water-based activities and when sleeping, according to established procedures [70]. The epoch length is analysed to $10 \mathrm{~s}$ to allow a more detailed estimate of PA intensity. The screening and data processing procedures to estimate sedentary time, total PA and PA at different intensities are consistent with previous studies in children and adolescents [70,71].

Body dissatisfaction. The Body Image Dimensional Assessment (BIDA) questionnaire [72] will be used. This is a silhouette-based scale that uses neutral figural stimuli to assess the subjective and affective dimensions of body image. This self-report scale consists of 4 questions referring to 4 figures on a scale ranging from 1.8 to 5.2 (range 3.4). The four silhouettes are not gender-, or ethnic-, or age-related, to focus the observer's attention on body shape: (1) Which figure do you think you currently look like? (2) Which is your ideal figure? (3) Which is the most attractive figure for the opposite sex? and (4) How do most people of your own sex and age look? 
Adherence to the Mediterranean diet. This instrument provides a Mediterranean Diet Quality Index in children and adolescents (KIDMED). The development of the KIDMED index will be based on principles sustaining Mediterranean eating patterns as well as those that undermine it [73]. This questionnaire consists of 16 yes/no questions, 12 with a positive connotation and four with a negative connotation with respect to the Mediterranean Diet (MeD). Positive questions are assigned a value of +1 : (e.g., fruit or fruit juice daily, second fruit every day, etc.). Negative questions are assigned a value of -1 (e.g., consumption of fast foods more than once a week, skipping breakfast, etc.). The index of adherence to the $\mathrm{MeD}$ is calculated as the sum of all the responses and ranges from 0 to 12. Levels of adherence are classified into three groups: poor adherence (0-3), average adherence (4-7) and good adherence (8-12) to the MeD [73]. Poor adherence is categorized as "Poor Diet" and average adherence and good adherence are categorized as "Average Diet" and "Good Diet", respectively.

Self-Esteem. The Spanish version of the Rosenberg Self-Esteem Scale (RSE) [74] will be used. The RSE is a 10-item self-report questionnaire assessing global self-esteem. Items are scored from 1 to 4 $(1=$ strongly agree, 2 = agree, $3=$ disagree, $4=$ strongly disagree $)$, and it is thought to represent a single trait of global self-esteem [17]. Five items are negatively worded (numbers 3, 5, 8, 9 and 10) and five items are positively worded.

Regulation of behaviour in physical exercise. To evaluate the students' underlying motivational regulation towards participation, the 19-item Behavioural Regulation in Exercise Questionnaire (BREQ-2) [75] will be conducted. It comprises five regulation or motivational subscales: (1) Intrinsic, (2) Identified, (3) Introjected, (4) External and (5) Amotivation. Responses were made on a 5-point Likert scale with verbal anchors affixed to "0" (Not true for me), "2" (Sometimes true for me) and " 4 " (Very true for me) [76]. The relative autonomy index is a composite score used to indicate the degree to which a person's exercise motivation is intrinsic or self-determined. The relative autonomy index is calculated by multiplying each Behavioural Regulation subscale score by a specific weight and then summing the weighted scores. The maximum score for the RAI is +20 , whereas the minimum is -24 , with higher positive scores indicating more intrinsic motivation [26]. For example, Item 1 is an External Regulation statement (-2 weight) "I exercise because people say I should." If the respondent chooses 2 (on a scale of $0-4$ ), the score (2) is multiplied by the weight (-2), obtaining a score of -4 for this item.

Satisfaction with life. This aspect was evaluated with the Satisfaction With Life Scale (SWLS, [77]). The scale has 5 items rated on a 5-point Likert scale, ranging from 1 (totally disagree) to 5 (totally agree). The present investigation will use the Spanish version of the SWLS [78].

Positive and negative affect. The Positive and Negative Affect Scale (PANAS) [79] presents 10 adjectives that reflect positive affect (e.g., interested) and 10 adjectives that represent negative affect (e.g., distressed). Positive and negative adjectives will be mixed and presented in two columns, as shown by Watson et al. [79]. Participants rated each adjective on a 5-point scale ranging from 1 (very slightly or not at all) to 5 (extremely).

(C) Anthropometric measure

All measurements included in the battery used ALPHA-Fitness battery. ALPHA-Fitness was developed to provide a set of valid, reliable, safe and viable field tests, whose objective was to develop a battery to measure the health-related fitness in youths of the countries of the European Union [80,81].

Anthropometric measurements will be performed in a designated private location to ensure discretion and comfort of the participants.

Weight and height. Weight is recorded to the nearest $0.1 \mathrm{~kg}$ using an electronic scale (model SECA 877) with participants dressed in lightweight clothing and without shoes. Height is measured to the nearest $1 \mathrm{~mm}$ using a telescopic height-measuring instrument. Body mass index was calculated as weight $(\mathrm{kg}) /$ height $\left(\mathrm{m}^{2}\right)$. Anthropometric measures were performed twice and the average was recorded.

Skinfold. Triceps and subscapular skinfold thickness are measured on the nondominant side of the body with a Holtain caliper (range, 0 to $40 \mathrm{~mm}$; precision, $0.2 \mathrm{~mm}$ ). The triceps are raised in a vertical fold halfway between the acromion process and the superior head of the radius, on the back of the arm. The subscapular skinfold is measured about $20 \mathrm{~mm}$ below the inferior angle of the 
scapula and $45^{\circ}$ to the lateral side of the body. It is performed according to Lohman's anthropometric standardization reference manual [82]. Triceps and subscapular skinfold thickness are measured twice, but not consecutively, and mean of the two measurements is used in the analyses. Percentage Body Fat will be calculated from triceps and subscapular skinfold thicknesses, using the equations developed by Slaughter et al. [83].

Waist circumference. Waist circumference is measured with a nonelastic tape measure (SECA 200; range, 0 to $150 \mathrm{~cm}$; precision, $1 \mathrm{~mm}$ ), at the level of the natural waist, on a horizontal plane, which is the narrowest part of the torso, as seen from the front. In some obese participants, it is difficult to identify the waist circumference; therefore, this measurement is performed in the midpoint between the superior iliac spine and the costal edge in the maxillary line [84]. The measurements are taken at the end of a normal expiration, without the tape compressing the skin. The measurements are carried out twice, but not consecutively, and mean of the two measurements is used in the analyses.

Neck circumference. This test does not belong in the ALPHA Fitness battery. Neck circumference (NC) is assessed with the participants standing in an erect position, with arms hanging freely and the head aligned in the Frankfort horizontal plane. The upper border of a nonelastic tape measure (SECA 200; range, $0-150 \mathrm{~cm}$; precision, $1 \mathrm{~mm}$ ) is placed just below the laryngeal prominence and applied perpendicularly to the long axis of the neck.

(D) Physical fitness

All health related fitness measurements included in the ALPHA-Fitness battery will be used. The physical fitness tests will be done at school recess.

Cardiorespiratory fitness. Cardiorespiratory fitness (CRF) will be evaluated with the 20-m shuttle run test. The participants are required to run between two lines $20 \mathrm{~m}$ apart, while keeping pace with audio signals emitted from a prerecorded CD. The initial speed is $8.5 \mathrm{~km} / \mathrm{h}$ and is increased by $0.5 \mathrm{~km} / \mathrm{h}$ per minute (one minute equals one stage). Participants are instructed to run in a straight line, to pivot on completing a shuttle and to pace themselves in accordance with the audio signals. The test concludes when the participant fails to reach the end lines concurrent with the audio signals on two consecutive occasions or when the subject stops because of fatigue. Participants are encouraged to keep running as long as possible throughout the test. The test is performed once, and the last completed stage or half-stage at which the subject dropped out is scored. A gymnasium or space large enough to mark out a 20-m track will be used to perform the test.

Handgrip strength. A hand dynamometer with adjustable grip (TKK 5101 Grip D; Takey, Tokio, Japan) will be used for this test. This dynamometer presents a high validity and reliability when compared with calibrated known weights [85]. The participant squeezes gradually and continuously for at least two seconds, performing the test with the right and left hands in turn, and with the elbow in full extension as described elsewhere [85]. The grip-span of the dynamometer is adjusted according to the hand size to determine the maximum handgrip strength using the equations specifically developed for children [86] and adolescents [87]. The test is performed twice and the maximum score for each hand is recorded in kilograms. The sum of the scores achieved by left and right hands is used in the analysis.

Lower limb strength. Lower limb strength will be evaluated with the standing long jump test. The subject will place behind the initial line and feet shoulder width apart. The participant jumps as far forward as possible on a nonslip hard surface. The test is performed twice, and the best score is recorded in centimetres.

$4 \times 10 \mathrm{~m}$ shuttle run test. The $4 \times 10$-m shuttle run is an adaptation of the $5 \times 10$-m shuttle run test included in the EUROFIT battery [38], maintaining the same characteristics. Velocity, agility and coordination are assessed in this test. The participant will run $10 \mathrm{~m}$ four times (back and forth) as fast as possible. The test is performed twice and the best score is recorded in hundredths of a second. 


\subsubsection{Development of the Sessions}

It will last 21 weeks (without the evaluation weeks). To achieve greater adherence and motivation in the program, numerous methodological and motivational strategies will be designed based on the interests of participants, based on the postulates of the SDT [65]. The aim will be promoted and the practice of out-of-school PA will be consolidated, in order to increase PA levels and sedentary behaviour (i.e., screen time). The development of sessions will take place in the afternoon, outside of school hours. They will be led by a qualified monitor. The monitors/trainers qualified will be graduates in sports sciences and will not be part of the research team. Moreover, these monitors/trainers will receive $15 \mathrm{~h}$ of specific training on the SDT by research team, divided into three to five hour classes (similar to other studies carried out with SDT programs) $[57,88]$. In addition, to supervise the program, a member of the research team (who are experts in the development of motivational strategies in the PA and Physical Education context) will be randomly present during some sessions. The monitor/trainers will not be previously informed to avoid influencing the development of the session. Regarding promoting social relationship, several strategies will be developed. Firstly, a WhatsApp group will be created in which information related to PA and healthy-related behaviours will be shared, with the aim to promote the interaction between the participants. In addition, there will also be two coexistence sessions, in which there will be two bicycle routes to the natural environment, with all the participants of the experimental group.

The activities of the intervention will go directly to developing the basic physical capacities: strength, endurance, speed and flexibility. The plan of the program is shown in Table 2. Every day, the research team will check that the activities room maintains optimal security conditions (e.g., ventilation, lighting, that the floor is not slippery, etc.). However, the risk that the students drop out of the intervention does not depend on us. In this regard, the issue that depends on us is developing strategies to avoid drop out, as well as to increase the adherence of students who are against the possibility of leaving the intervention. In this sense, based on previous investigation [85], strategies will be developed to promote the autonomy support such as to foster pupils' active participation; activities that increase the pressure to win will be avoided to reduce the competitiveness. In order to promote competence, support for the activities will be adapted to the levels of the participants to avoid frustration, as well as to carry out activities where success is evaluated through intrapersonal instead of interpersonal indicators, in addition to providing positive feedback so that students feel safer when carrying out the tasks. Regarding relatedness support, socialization will be promoted among all members, in addition to promoting the mixed-gender groups. In addition, stereotypical activities and sports with excessive competition will be avoided. Give free time during the development of the sessions/classes (with the aim that individuals promote their relatedness and speak about different parts of the session; a greater confidence and lack of inhibition is promoted); develop heterogeneous ways of grouping (i.e., promoting integration and cohesion); teach individuals in social skills (i.e., teach them to show empathy through peers and teacher/coach; diary dedication by teacher/trainer); plan cooperative and group dynamics activities (i.e., help continue work in a common purpose, enjoyment in the session/class to improve motivation).

\subsubsection{Final Measure}

This will last 1 week. The same measurements as in the initial evaluation will be repeated. This will allow intergroup and intragroup comparisons to assess the effect of the program.

\subsubsection{Follow-up Postintervention}

Three months later, there will be a follow-up post intervention to know if the changes produced over time are maintained. It will last for three weeks, during which the members of the EG and CG will be revised. 
Table 2. Training planning of Multidisciplinary Program.

\begin{tabular}{|c|c|c|c|c|c|}
\hline Phases & Weeks & Aerobic Training & Strength Training & Socialization & Speed \\
\hline \multirow{4}{*}{ Familiarization } & 1 & \multicolumn{4}{|c|}{ INITIAL MEASURE } \\
\hline & 2 & $X X$ & $\mathrm{X}$ & $X X X$ & $X$ \\
\hline & 3 & $X$ & $x$ & $X X X$ & $x$ \\
\hline & 4 & $x X$ & $x$ & $X X$ & $x$ \\
\hline \multirow{4}{*}{ Month 1} & 5 & $X X$ & $X$ & $X X$ & $X X$ \\
\hline & 6 & $X X$ & $X X$ & $X X$ & $X$ \\
\hline & 7 & $x X$ & $X X$ & $X X$ & $x x$ \\
\hline & 8 & $X$ & $x X$ & $X X$ & $X$ \\
\hline \multirow{4}{*}{ Month 2} & 9 & $X$ & $X X$ & $X X X$ & $X X$ \\
\hline & 10 & $X X$ & $X X$ & $X X$ & $X$ \\
\hline & 11 & $X X$ & $X$ & $X X$ & $X X$ \\
\hline & 12 & $X X$ & $x$ & $X X$ & $X$ \\
\hline \multirow{5}{*}{ Month 3} & 13 & $X$ & $X$ & $X X$ & $X X$ \\
\hline & 14 & $X$ & $X X$ & $X X$ & $X$ \\
\hline & 15 & $X X$ & $X X$ & $X X$ & $X X$ \\
\hline & 16 & $x X$ & $x$ & $X X$ & $x$ \\
\hline & 17 & $X$ & $X X$ & $X X$ & $x$ \\
\hline \multirow{6}{*}{ Month 4} & 18 & $x$ & $X$ & $X X X$ & $X X$ \\
\hline & 19 & $X$ & $X X$ & $X X$ & $X$ \\
\hline & 20 & $x X$ & $X$ & $X X$ & $x$ \\
\hline & 21 & $X X$ & $X$ & $X X$ & $X$ \\
\hline & 22 & $X$ & $\mathrm{x}$ & $X X X$ & $x$ \\
\hline & 23 & \multicolumn{4}{|c|}{ FINAL MEASURE } \\
\hline \multicolumn{2}{|c|}{3 months later } & \multicolumn{4}{|c|}{ FOLLOW-UP POST INTERVENTION } \\
\hline
\end{tabular}

Note. X: Low priority, XX: Medium priority, XXX: High priority.

\subsection{Statistical Analysis}

A code will be assigned to each student to maintain the confidentiality of the data. The students who attended less than $80 \%$ of the sessions will be deleted for data analysis. The normality of the variables will be verified, and the results expressed as means, standard deviation, medians or different ranges. To evaluate possible predictors, multiple regression analysis will be performed on the independent variables of sedentary lifestyle, PA, anthropometric variables or health-related fitness and psychosocial variables. The comparisons of the intergroup and intragroup program will be analysed by ANOVA of repeat measures, the McNemars' test and nonparametric tests like Kruskall-Wallis method, as well as Chi-squared tests, as appropriate. General linear models such as ANOVA, UNIANOVA, MANOVA, etc. will also be used to evaluate the effects of training among groups. The mediation or moderation analyses will be conducted as appropriate, using the PROCESS macro for SPSS.

\section{Discussion}

The main aim of this study is to assess an effectiveness of the Multidisciplinary Training Program for the Promotion of PA and Healthy Lifestyle in Inactive Adolescents". Thus, this program aims to achieve the increasing of PA levels through the inclusion of motivational strategies.

According to the main aim, and up to our knowledge, this would be the first study to promote PA and health-related habits taking into account heterogeneity of the sample based on SDT with adolescents inactive. There are many previous $[17,26,46,47,60]$ studies that have shown the positive effect of PA and the promotion of health-related habits in adolescents. However, as mentioned above, none of them took into account the individuals' heterogeneity [25].

In this sense, the results obtained will allow us to determine whether a PA promotion program based on the SDT produces a positive effect on the behaviours related to the health of inactive and 
sedentary adolescents. Despite previous programs, the Multidisciplinary Program will take into account individuals' interests to implement the program's sessions, based on their preferences when practicing PA. To achieve this purpose, sessions will be planned weekly, asking students about the content or activities they want to do throughout the week. In addition, homogenization of the sample based on the PA level will increase the autonomy of the participants because participants with low PA levels will not be compared with those with high PA.

Regarding the impact of the project, there are several benefits that can be obtained. The findings of the study "Multidisciplinary Training Program for the Promotion of PA and Healthy Lifestyle in Inactive Adolescents" can help Health Information Systems and politician's makers to identify the target population for primary prevention and health prevention policies with the intention to develop and promote strategies that help promote healthy habits.

However, despite the important contributions expected, this project is not without limitations. Firstly, a cost-effectiveness evaluation was not included in the program, which is relevant to know the effects of the intervention developed in order to enhance the positive consequences. Secondly, the strategies suggested for behaviour change in a health behaviour intervention context were conducted. Regarding cost-effectiveness evaluation, it would be important for future interventions to carry out a cost-effectiveness evaluation. Finally, it was not evaluated whether participation in the Multidisciplinary Program increased their involvement and motivation during Physical Education lessons. This limitation could be an important aspect to consider for future interventions to develop outside of school hours. It would be interesting to carry out interviews with the Physical Education teachers to follow up on the participants of the program during the Physical Education lessons-for example, to know if the participants get involved during the Physical Education lessons, if they have a greater interest in PA and if the teachers see the students of the program more motivated in their lessons.

Finally, throughout the project, the research team hopes to get the following publications:

Study 1: to develop a training program based on methodological strategies aimed at optimizing the level of satisfaction of BPN. Moreover, to know the motivation for practice to modify behaviour patterns in inactive adolescents.

Study 2: to check to what extent the modification of autonomous behaviour promotes an improvement in PA, and their effect on physical condition, fatness and other healthy habits. In addition, the study aims to determine if the effect of the intervention will be different in boys and girls. Furthermore, to determine if the increase in PA produced by the modification of autonomous behaviour is different in boys than in girls.

Study 3: The reliability and validity of the BIDA instrument in adults has been demonstrated [72]. Given the importance of this instrument to assess body dissatisfaction, we intend to validate this instrument for Spanish adolescents.

\section{Conclusions}

This project will investigate the effect about health-related behaviours of a PA program based on SDT in adolescents. In addition, the results of this study will be important to know the habits of Extremadura adolescents and to be able to undertake the pertinent interventions to attend to this situation. Moreover, orientations will be given to transfer the obtained results to the public sector to evaluate or change the adopted policies about health promotion.

Supplementary Materials: The following are available online at http://www.mdpi.com/2071-1050/12/15/5893/s1, Table S1: Variables and instruments of the initial measure.

Author Contributions: P.A.S.-M. and M.A.T.-S.: design, instrument selection and manuscript preparation, P.A.S.-M.; M.V.-S. and D.S.O.: review of the manuscript, D.S.-O., J.J.P.; M.A.L.-G. and M.A.T.-S.: design and instrument selection: P.A.S.-M.; M.A.L.-G. and M.A.T.-S., writing-original draft. P.A.S.-M.; M.V.-S.; D.S.-O.; J.J.P.; M.A.L.-G. and M.A.T.-S., writing-review and editing. All authors have read and agreed to the published version of the manuscript. 
Funding: This study was funded by the European Community and Ministry of Economy of Extremadura (IB16193).

Acknowledgments: We gratefully acknowledge the financial support of the Ministry of Economy and Infrastructures and European Community. The authors wish to thank the schools, children and their parents who generously volunteered to participate in the study. We also acknowledge all the staff members involved in the fieldwork for their efforts and great enthusiasm. JJP also thanks the European Social Foundation and the Government of Extremadura for a postdoctoral grant (PO17012).

Conflicts of Interest: The author(s) declared no potential conflict of interest with respect to the research, authorship and/or publication of this article.

\section{References}

1. World Health Organización. Global Recommendations on Physical Activity for Health; World Health Organization, 2010; Available online: https://apps.who.int/iris/bitstream/handle/10665/44399/9789241599979_eng.pdf; jsessionid=F4695575142FAB14D76A83F157002A76? sequence $=1$ (accessed on 6 July 2020).

2. Abarca-Gómez, L.; Abdeen, Z.A.; Hamid,Z.A.; Abu-Rmeileh, N.M.; Acosta-Cazares, B.; Acuin, C.; Adams, R.J.; Aekplakorn, W.; Afsana, K.; Aguilar-Salinas, C.A.; et al. NCD Risk Factor Collaboration (NCD-RisC). Worldwide trends in body-mass index, underweight, overweight, and obesity from 1975 to 2016: A pooled analysis of 2416 population-based measurement studies in 128.9 million children, adolescents, and adults. Lancet 2017, 390, 2627-2642. [CrossRef]

3. Akhtar-Danesh, N.; Dehghan, M.; Morrison, K.M.; Fonseka, S. Parents' perceptions and attitudes on childhood obesity: A Q-methodology study. J. Am. Acad. Nurse Pract. 2011, 23, 67-75. [CrossRef] [PubMed]

4. Cooper, A.R.; Goodman, A.; Page, A.S.; Sherar, L.B.; Esliger, D.W.; van Sluijs, E.M.F.; Andersen, L.B.; Anderssen, S.; Cardon, G.; Davey, R.; et al. Objectively measured physical activity and sedentary time in youth: The International children's accelerometry database (ICAD). Int. J. Behav. Nutr. Phys. Act. 2015, 12, 1-10. [CrossRef] [PubMed]

5. Kalman, M.; Inchley, J.; Sigmundova, D.; Iannotti, R.J.; Tynjala, J.A.; Hamrik, Z.; Haug, E.; Bucksch, J. Secular trends in moderate-to-vigorous physical activity in 32 countries from 2002 to 2010: A cross-national perspective. Eur. J. Public Health 2015, 25, 37-40. [CrossRef] [PubMed]

6. Cliff, D.P.; Hesketh, K.D.; Vella, S.A.; Hinkley, T.; Tsiros, M.D.; Ridgers, N.D.; Carver, A.; Veitch, J.; Parrish, A.M.; Hardy, L.L.; et al. Objectively measured sedentary behaviour and health and development in children and adolescents: Systematic review and meta-analysis. Obes. Rev. 2016, 17, 330-344. [CrossRef] [PubMed]

7. Pinto, S.M.P.; Power, C. Change in health and social factors in mid-adulthood and corresponding changes in leisure-time physical inactivity in a prospective cohort. Int. J. Behav. Nutr. Phys. Act. 2018, 15, 89. [CrossRef]

8. Guthold, R.; Stevens, G.A.; Riley, L.M.; Bull, F.C. Global trends in insufficient physical activity among adolescents: A pooled analysis of 298 population-based surveys with 1.6 million participants. Lancet Child Adolesc. Heal. 2020, 4, 23-35. [CrossRef]

9. Unión Europea. Traducción e impresión Consejo Superior de Deportes. CSD. Directrices Act; Física Ue Madrid: Madried, Spain, 2008.

10. Sallis, J.F.; Owen, N. Ecological Models of Health Behavior. In Health Behavior and Health Education: Theory, Research and Practice, 3rd ed.; Jossey-Bass: San Francisco, CA, USA, 2002.

11. Demetriou, Y.; Bachner, J. A school-based intervention based on self-determination theory to promote girls' physical activity: Study protocol of the CReActivity cluster randomised controlled trial. BMC Public Health 2019, 19, 1-9. [CrossRef]

12. Report: Tackling Physical Inactivity_A Coordinated Approach | All-Party Commission on Physical Activity on WordPress.com. Available online: https://activitycommission.com/report-tackling-physical-inactivity-acoordinated-approach (accessed on 6 July 2020).

13. Smith, J.J.; Morgan, P.J.; Plotnikoff, R.C.; Dally, K.A.; Salmon, J.; Okely, A.D.; Finn, T.L.; Lubans, D.R. Smart-phone obesity prevention trial for adolescent boys in low-income communities: The ATLAS RCT. Pediatrics 2014, 134, e723-e731. [CrossRef]

14. Jago, R.; Edwards, M.J.; Sebire, S.J.; Cooper, A.R.; Powell, J.E.; Bird, E.L.; Simon, J.; Blair, P.S. Bristol girls dance project (BGDP): Protocol for a cluster randomised controlled trial of an after-school dance programme to increase physical activity among 11-12 year old girls. BMC Public Health 2013, 13, 1003. [CrossRef] 
15. Alvirde-García, U.; Rodríguez-Guerrero, A.J.; Henao-Morán, S.; Gómez-Pérez, F.J.; Aguilar-Salinas, C.A. Results of a community based life style intervention program for children. Salud Publica Mex. 2013, 55, 406-414. [PubMed]

16. Jacobs, N.; Hagger, M.S.; Streukens, S.; De Bourdeaudhuij, I.; Claes, N. Testing an integrated model of the theory of planned behaviour and self-determination theory for different energy balance-related behaviours and intervention intensities. Br. J. Health Psychol. 2011, 16, 113-134. [CrossRef] [PubMed]

17. Pardo, B.M.; Bengoechea, E.G.; Julián Clemente, J.A.; Lanaspa, E.G. Empowering adolescents to be physically active: Three-year results of the Sigue la Huella intervention. Prev. Med. (Baltim) 2014, 66, 6-11. [CrossRef] [PubMed]

18. Sevil, J.; García-González, L.; Abós, Á.; Generelo, E.; Aibar, A. Can High Schools Be an Effective Setting to Promote Healthy Lifestyles? Effects of a Multiple Behavior Change Intervention in Adolescents. J. Adolesc. Heal. 2019, 64, 478-486. [CrossRef]

19. Michie, S.F.; West, R.; Campbell, R.; Brown, J.; Gainforth, H. ABC of Behaviour Change Theories; Silverback publishing: London, UK, 2014.

20. Brown, H.E.; Whittle, F.; Jong, S.T.; Croxson, C.; Sharp, S.J.; Wilkinson, P.; Wilson, E.C.; Van Sluijs, E.M.; Vignoles, A.; Corder, K. A cluster randomised controlled trial to evaluate the effectiveness and cost-effectiveness of the GoActive intervention to increase physical activity among adolescents aged 13-14 years. BMJ Open 2017, 7, e014419. [CrossRef]

21. Koorts, H.; Eakin, E.; Estabrooks, P.; Timperio, A.; Salmon, J.; Bauman, A. Implementation and scale up of population physical activity interventions for clinical and community settings: The PRACTIS guide. Int. J. Behav. Nutr. Phys. Act. 2018, 15, 51. [CrossRef]

22. Baranowski, T.; Jago, R. Understanding the Mechanisms of Change in Children's Physica...: Exercise and Sport Sciences Reviews. Exerc. Sport Sci. Rev. 2005, 33, 163-168. [CrossRef]

23. Ryan, R.M.; Deci, E.L. Intrinsic and Extrinsic Motivations: Classic Definitions and New Directions. Contemp. Educ. Psychol. 2000, 25, 54-67. [CrossRef]

24. Deci, E.L.; Tyan, R.M. The general causality orientations scale: Self-Determination in Personality. J. Res. Pers. 1985, 19, 109-134. [CrossRef]

25. Vaquero-Solís, M.; Gallego, D.I.; Tapia-Serrano, M.Á.; Pulido, J.J.; Sánchez-Miguel, P.A. School-based physical activity interventions in children and adolescents: A systematic review. Int. J. Environ. Res. Public Health 2020, 17, 999. [CrossRef]

26. Teixeira, P.J.; Carraça, E.V.; Markland, D.; Silva, M.N.; Ryan, R.M. Exercise, Physical Activity, and Self-Determination Theory: A Systematic Review; BioMed Central: London, UK, 2012; Volume 9, p. 78.

27. González-Cutre, D.; Sierra, A.C.; Beltrán-Carrillo, V.J.; Peláez-Pérez, M.; Cervelló, E. A school-based motivational intervention to promote physical activity from a self-determination theory perspective. J. Educ. Res. 2016, 111, 320-330. [CrossRef]

28. Sánchez-Oliva, D.; Pulido-González, J.J.; Leo, F.M.; González-Ponce, I.; García-Calvo, T. Effects of an intervention with teachers in the physical education context: A Self-Determination Theory approach. PLoS ONE 2017, 12, e0189986. [CrossRef] [PubMed]

29. Ryan, R.M.; Deci, E.L. Self-Determination Theory. Basic Psychological Needs in Motivation, Development and Wellness; Consortium Erudit; Guilford Press: New York, NY, USA, 2017; Volume 38.

30. Reeve, J.; Jang, H. What teachers say and do to support students' autonomy during a learning activity. J. Educ. Psychol. 2016, 98, 209-218. [CrossRef]

31. Ryan, R.M.; Deci, E.L. Intrinsic and extrinsic motivation from a self-determination theory perspective: Definitions, theory, practices, and future directions. Contemp. Educ. Psychol. 2020, 101860. [CrossRef]

32. Deci, E.; Ryan, R. "Facilitating optimal motivation and psychological well-being across life's domains": Correction to Deci and Ryan. Can. Psychol. Can. 2008, 49, 262. [CrossRef]

33. Corder, K.; Atkin, A.J.; Ekelund, U.; Van Sluijs, E.M. What do adolescents want in order to become more active? BMC Public Health 2013, 13, 718. [CrossRef]

34. Kriemler, S.; Meyer, U.; Martin, E.; Van Sluijs, E.M.F.; Andersen, L.B.; Martin, B.W. Effect of school-based interventions on physical activity and fitness in children and adolescents: A review of reviews and systematic update. Br. J. Sports Med. 2011, 45, 923-930. [CrossRef] 
35. Dobbins, M.; Husson, H.; Decorby, K.; Larocca, R.L. School-based physical activity programs for promoting physical activity and fitness in children and adolescents aged 6 to 18. Cochrane Database Syst. Rev. 2013, 2013. [CrossRef]

36. Lonsdale, C.; Rosenkranz, R.R.; Peralta, L.R.; Bennie, A.; Fahey, P.; Lubans, D.R. A systematic review and meta-analysis of interventions designed to increase moderate-to-vigorous physical activity in school physical education lessons. Prev. Med. 2013, 56, 152-161. [CrossRef]

37. Owen, K.B.; Smith, J.; Lubans, D.R.; Ng, J.Y.Y.; Lonsdale, C. Self-determined motivation and physical activity in children and adolescents: A systematic review and meta-analysis. Prev. Med. (Baltim) 2014, 67, 270-279. [CrossRef]

38. Castro-Piñero, J.; Carbonell-Baeza, A.; Martinez-Gomez, D.; Gómez-Martínez, S.; Cabanas-Sánchez, V.; Santiago, C.; Veses, A.M.; Bandrés, F.; Gonzalez-Galo, A.; Gomez-Gallego, F.; et al. Follow-up in healthy schoolchildren and in adolescents with DOWN syndrome: Psycho-environmental and genetic determinants of physical activity and its impact on fitness, cardiovascular diseases, inflammatory biomarkers and mental health; the UP\&amp study. BMC Public Health 2014, 14, 400.

39. Lonsdale, C.; Rosenkranz, R.R.; Sanders, T.; Peralta, L.R.; Bennie, A.; Jackson, B.; Taylor, I.M.; Lubans, D.R. A cluster randomized controlled trial of strategies to increase adolescents' physical activity and motivation in physical education: Results of the Motivating Active Learning in Physical Education (MALP) trial. Prev. Med. (Baltim) 2013, 57, 696-702. [CrossRef]

40. Robbins, L.; Wen, F.; Research, J.L. Mediators of Physical Activity Behavior Change in the "Girls on the Move" Intervention. Nurs. Res. 2019, 68, 257-266. [CrossRef] [PubMed]

41. Tremblay, M.S.; Carson, V.; Chaput, J.-P.; Connor Gorber, S.; Dinh, T.; Duggan, M.; Faulkner, G.; Gray, C.E.; Gruber, R.; Janson, K.; et al. Canadian 24-Hour Movement Guidelines for Children and Youth: An Integration of Physical Activity, Sedentary Behaviour, and Sleep. Appl. Physiol. Nutr. Metab. 2016, 41, S311-S327. [CrossRef] [PubMed]

42. Ericsson, I. Effects of increased physical activity on motor skills and marks in physical education: An intervention study in school years 1 through 9 in Sweden. Phys. Educ. Sport Pedagog. 2011, 16, 313-329. [CrossRef]

43. Faigenbaum, A.D.; Gipson-Jones, T.L.; Myer, G.D. Exercise Deficit Disorder in Youth. J. Sch. Nurs. 2012, 28, 252-255. [CrossRef]

44. Ardoy, D.N.; Fernández-Rodríguez, J.M.; Ruiz, J.R.; Chillón, P.; España-Romero, V.; Castillo, M.J.; Ortega, F.B. Improving Physical Fitness in Adolescents Through a School-Based Intervention: The EDUFIT Study. Rev. Española Cardiol. 2011, 64, 484-491. [CrossRef]

45. González-Gross, M.; Ruiz, J.R.; Moreno, L.A.; de Rufino-Rivas, P.; Garaulet, M.; Mesana, M.I.; Gutiérrez, A.; AVENAGroup*, T. Body composition and physical performance of Spanish adolescents: The AVENA pilot study. Acta Diabetol. 2003, 40, s299-s301. [CrossRef]

46. Naylor, P.-J.P.J.; Macdonald, H.M.; Zebedee, J.A.; Reed, K.E.; McKay, H.A. Lessons learned from Action Schools! BC-An 'active school'model to promote physical activity in elementary schools. J. Sci. Med. Sport 2006, 9, 413-423. [CrossRef]

47. Quaresma, A.M.; Palmeira, A.L.; Martins, S.S.; Minderico, C.S.; Sardinha, L.B. Effect of a school-based intervention on physical activity and quality of life through serial mediation of social support and exercise motivation: The PESSOA program. Health Educ. Res. 2014, 29, 906-917. [CrossRef]

48. Kowalski, K.C.; Crocker, P.R.E.; Donen, R.M. The Physical Activity Questionnaire for Older Children (PAQ-C) and Adolescents (PAQ-A) Manual; College of Kinesiology, University of Saskatchewan, 2013; Available online: https:/www.researchgate.net/profile/Peter_Crocker/publication/228441462_The_ Physical_Activity_Questionnaire_for_Older_Children_PAQ-C_and_Adolescents_PAQ-A_Manual/links/ 00b7d51a37fe869464000000.pdf (accessed on 7 July 2020).

49. Martínez-Gómez, D.; Martínez-de-Haro, V.; Pozo, T.; Welk, G.J.; Villagra, A.; Calle, M.E.; Marcos, A.; Veiga, O.L. Fiabilidad y validez del cuestionario de actividad física PAQ-A en adolescentes españoles. Rev. Esp. Salud Publica 2009, 83, 427-439. [CrossRef] [PubMed]

50. Telama, R.; Yang, X. Decline of physical activity from youth to young adulthood in Finland. Med. Sci. Sport. Exerc. 2000, 32, 1617-1622. [CrossRef] 
51. Cabanas-Sánchez, V.; Martínez-Gómez, D.; Esteban-Cornejo, I.; Castro-Piñero, J.; Conde-Caveda, J.; Veiga, Ó.L. Reliability and validity of the Youth Leisure-time Sedentary Behavior Questionnaire (YLSBQ). J. Sci. Med. Sport 2018, 21, 69-74. [CrossRef] [PubMed]

52. Amoura, C.; Berjot, S.; Gillet, N.; Caruana, S.; Cohen, J.; Finez, L. Autonomy-Supportive and Controlling Styles of Teaching. Swiss J. Psychol. 2015, 74, 141-158. [CrossRef]

53. Jang, H.; Reeve, J.; Ryan, R.M.; Kim, A. Can Self-Determination Theory Explain What Underlies the Productive, Satisfying Learning Experiences of Collectivistically Oriented Korean Students? J. Educ. Psychol. 2009, 101, 644-661. [CrossRef]

54. Haerens, L.; Aelterman, N.; Vansteenkiste, M.; Soenens, B.; Van Petegem, S. Do perceived autonomy-supportive and controlling teaching relate to physical education students' motivational experiences through unique pathways? Distinguishing between the bright and dark side of motivation. Psychol. Sport Exerc. 2015, 16, 26-36. [CrossRef]

55. Taylor, I.M.; Ntoumanis, N.; Standage, M.; Spray, C.M. Motivational predictors of physical education students' effort, exercise intentions, and leisure-time physical activity: A multilevel linear growth analysis. J. Sport Exerc. Psychol. 2010, 32, 99-120. [CrossRef]

56. Vasconcellos, D.; Parker, P.D.; Hilland, T.; Cinelli, R.; Owen, K.B.; Kapsal, N.; Lee, J.; Antczak, D.; Ntoumanis, N.; Ryan, R.M.; et al. Self-Determination Theory Applied to Physical Education: A Systematic Review and Meta-Analysis. J. Educ. Psychol. 2019. [CrossRef]

57. Sánchez-Oliva, D.; Sánchez-Miguel, P.A.; Kinnafick, F.-E.; Leo, F.M.; García-Calvo, T. Physical education lessons and physical activity intentions within Spanish Secondary Schools: A Self-Determination perspective. J. Teach. Phys. Educ. 2014, 33, 232-249. [CrossRef]

58. Reeve, J. Why teachers adopt a controlling motivating style toward students and how they can become more autonomy supportive. Educ. Psychol. 2009, 44, 159-175. [CrossRef]

59. Cox, A.; Williams, L. The roles of perceived teacher support, motivational climate, and psychological need satisfaction in students' physical education motivation. J. Sport Exerc. Psychol. 2008, 30, 222-239. [CrossRef] [PubMed]

60. Ardoy, D.N.; Fernández-Rodríguez, J.M.; Chillón, P.; Artero, E.G.; España-Romero, V.; Jiménez-Pavón, D.; Ruiz, J.R.; Guirado-Escámez, C.; Castillo, M.J.; Ortega, F.B. Educando para mejorar el estado de forma física, estudio EDUFIT: Antecedentes, diseño, metodología y análisis del abandono/adhesión al estudio. Rev. Esp. Salud Publica 2010, 84, 151-168. [CrossRef] [PubMed]

61. Cheon, S.H.; Reeve, J.; Ntoumanis, N. A needs-supportive intervention to help PE teachers enhance students' prosocial behavior and diminish antisocial behavior. Psychol. Sport Exerc. 2018, 35, 74-88. [CrossRef]

62. Lonsdale, C.; Lester, A.; Owen, K.B.; White, R.L.; Peralta, L.; Kirwan, M.; Diallo, T.M.O.; Maeder, A.J.; Bennie, A.; Macmillan, F.; et al. An internet-supported school physical activity intervention in low socioeconomic status communities: Results from the Activity and Motivation in Physical Education (AMPED) cluster randomised controlled trial. Br. J. Sports Med. 2017, 53, 341-347. [CrossRef]

63. World Health Organization. Global Tuberculosis Control: WHO Report 2010; World Health Organization: Geneva, Switzerland, 2010.

64. Garber, C.E.; Blissmer, B.; Deschenes, M.R.; Franklin, B.A.; Lamonte, M.J.; Lee, I.-M.; Nieman, D.C.; Swain, D.P.; American College of Sports Medicine American College of Sports Medicine position stand. Quantity and quality of exercise for developing and maintaining cardiorespiratory, musculoskeletal, and neuromotor fitness in apparently healthy adults: Guidance for prescribing exercise. Med. Sci. Sports Exerc. 2011, 43, 1334-1359. [CrossRef]

65. Deci, E.L.; Ryan, R.M. The "What" and "Why" of Goal Pursuits: Human Needs and the Self-Determination of Behavior. Psychol. Inq. 2000, 11, 227-268. [CrossRef]

66. Currie, C.; Molcho, M.; Boyce, W.; Holstein, B.; Torsheim, T.; Richter, M. Researching health inequalities in adolescents: The development of the Health Behaviour in School-Aged Children (HBSC) Family Affluence Scale. Soc. Sci. Med. 2008, 66, 1429-1436. [CrossRef]

67. Robusto, K.M.; Trost, S.G. Comparison of three generations of ActiGraph ${ }^{\mathrm{TM}}$ activity monitors in children and adolescents. J. Sports Sci. 2012, 30, 1429-1435. [CrossRef]

68. Vanhelst, J.; Mikulovic, J.; Bui-Xuan, G.; Dieu, O.; Blondeau, T.; Fardy, P.; Béghin, L. Comparison of two ActiGraph accelerometer generations in the assessment of physical activity in free living conditions. BMC Res. Notes 2012, 5, 187. [CrossRef] 
69. Rothney, M.P.; Apker, G.A.; Song, Y.; Chen, K.Y. Comparing the performance of three generations of ActiGraph accelerometers. J. Appl. Physiol. 2008, 105, 1091-1097. [CrossRef]

70. Ward, D.S.; Evenson, K.R.; Vaughn, A.; Rodgers, A.B.; Troiano, R.P. Accelerometer use in physical activity: Best practices and research recommendations. Med. Sci. Sports Exerc. 2005, 37, S582-S588. [CrossRef] [PubMed]

71. Ortega, F.B.; Konstabel, K.; Pasquali, E.; Ruiz, J.R.; Hurtig-Wennlöf, A.; Mäestu, J.; Löf, M.; Harro, J.; Bellocco, R.; Labayen, I.; et al. Objectively Measured Physical Activity and Sedentary Time during Childhood, Adolescence and Young Adulthood: A Cohort Study. PLoS ONE 2013, 8, e60871. [CrossRef] [PubMed]

72. Segura-García, C.; Papaianni, M.C.; Rizza, P.; Flora, S.; Fazio, P. De The development and validation of the Body Image Dimensional Assessment (BIDA). Eat. Weight Disord. Stud. Anorexia Bulim. Obes. 2012, 17, e219-e225.

73. Serra-Majem, L.; Ribas, L.; Ngo, J.; Ortega, R.M.; García, A.; Pérez-Rodrigo, C.; Aranceta, J. Food, youth and the Mediterranean diet in Spain. Development of KIDMED, Mediterranean Diet Quality Index in children and adolescents. Public Health Nutr. 2004, 7, 931-935. [CrossRef]

74. Vázquez, A.J.; Rosa, M.; García-Bóveda, J. Escala de autoestima de Rosenberg: Fiabilidad y validez en población clínica española. Apunt. Psicol. 2004, 22, 247-255.

75. Markland, D.; Tobin, V. A modification to the behavioural regulation in exercise questionnaire to include an assessment of amotivation. J. Sport. Exerc. 2004, 26, 191-196. [CrossRef]

76. Wilson, P.M.; Sabiston, C.M.; Mack, D.E.; Blanchard, C.M. On the nature and function of scoring protocols used in exercise motivation research: An empirical study of the behavioral regulation in exercise questionnaire. Psychol. Sport Exerc. 2012, 13, 614-622. [CrossRef]

77. Diener, E.; Eunkook, M.S.; Richard, E.L.; Heidi, L.S. Subjective Well-Being: Three Decades of Progress. Psychol. Bull. 1984, 95, 542-575. [CrossRef]

78. Atienza, F.; Balaguer, I.; García-Merita, M. Propiedades Psicométricas de la Escala de Satisfacción con la Vida en Adolescentes. Psicothema 2000, 12, 314-319.

79. Watson, D.; Clark, L.A.L.A.; Tellegen, A. Development and Validation of Brief Measures of Positive and Negative Affect. PANAS Scales 1988, 54, 1063-1070.

80. Ruíz, J.R.; España Romero, V.; Castro Piñero, J.; Artero, E.G.; Ortega, F.B.; Cuenca García, M.; Jiménez Pavón, D.; Chillón, P.; Girela Rejón, M.J.; Mora, J.; et al. Batería ALPHA-Fitness: Test de campo para la evaluación de la condición física relacionada con la salud en niños y adolescentes. SciELO Esp. 2011, 26, 1210-1214.

81. Ruiz, J.R.; Castro-Piñero, J.; España-Romero, V.; Artero, E.G.; Ortega, F.B.; Cuenca, M.A.M.; Enez-Pavón, D.J.; Chillón, P.; Girela-Rejón, M.J.; Mora, J.; et al. Field-based fitness assessment in young people: The ALPHA health-related fitness test battery for children and adolescents. Br. J. Sports Med. 2011, 45, 518-524. [CrossRef] [PubMed]

82. Lohman, T.; Roche, A.F.; Matorell, R. Anthropometric Standardization Reference Manual; Human Kinetics: Champaign, IL, USA, 1991.

83. Slaughter, M.; Lohman, T.; Boileau, R.; Horswill, C.; Stillman, R.; Loan, V.; Bemben, D. Skinfold Equations for Estimation of Body Fatness in Children. Biology (Basel) 1988, 60, 709-723.

84. Nagy, E.; Vicente-Rodriguez, G.; Manios, Y.; Béghin, L.; Iliescu, C.; Censi, L.; Dietrich, S.; Ortega, F.B.; De Vriendt, T.; Plada, M.; et al. Harmonization process and reliability assessment of anthropometric measurements in a multicenter study in adolescents. Int. J. Obes. 2008, 32, S58-S65. [CrossRef] [PubMed]

85. España-Romero, V.; Ortega, F.B.; Vicente-Rodríguez, G.; Artero, E.G.; Rey, J.P.; Ruiz, J.R. Elbow Position Affects Handgrip Strength in Adolescents: Validity and Reliability of Jamar, DynEx, and TKK Dynamometers. J. Strength Cond. Res. 2010, 24, 272-277. [CrossRef] [PubMed]

86. España-Romero, V.; Artero, E.G.; Santaliestra-Pasias, A.M.; Gutierrez, A.; Castillo, M.J.; Ruiz, J.R. Hand Span Influences Optimal Grip Span in Boys and Girls Aged 6 to 12 Years. J. Hand Surg. Am. 2008, 33, 378-384. [CrossRef]

87. Ruiz, J.R.; España-Romero, V.; Ortega, F.B.; Sjöström, M.; Castillo, M.J.; Gutierrez, A. Hand Span Influences Optimal Grip Span in Male and Female Teenagers. J. Hand Surg. Am. 2006, 31, 1367-1372. [CrossRef]

88. García-Calvo, T.; Sánchez-Oliva, D.; Leo, F.M.; Amado, D.; Pulido, J.J. Effects of an intervention programme with teachers on the development of positive behaviours in Spanish physical education classes. Phys. Educ. Sport Pedagog. 2016, 21, 572-588. [CrossRef] 
(C) 2020 by the authors. Licensee MDPI, Basel, Switzerland. This article is an open access article distributed under the terms and conditions of the Creative Commons Attribution (CC BY) license (http://creativecommons.org/licenses/by/4.0/). 